\title{
0275 ANALYSIS OF FATAL BUS CRASHES IN BANGALORE,
} INDIA

G Gururaj* Correspondence: Department of epidemiology, National Institute of mental Health and Neuro Sciences, WHO CC for Injury Prevention and Safety promotion, NIMHANS, Bangalore 560029, India

\subsection{6/ip.2010.029215.275}

Growth of motor vehicles and infrastructure expansion are hall marks of transport development in the last decade in India. Public transport buses in Bangalore city has increased from 2300 in 2002 to 5300 by 2009 with expansion of coverage, trips and users, with a corresponding increase in road crashes and deaths.

The study is part of the ongoing Bangalore Road safety and Injury Prevention Programme. The objectives were to examine (1) the contribution of public transport buses in road crashes and (2) crash characteristics of collisions involving buses. Data collection were undertaken from records by trained personnel.

On an average, 100-120 buses are involved in fatal collisions and 400-500 in non-fatal crashes every year, with an increase of deaths from 58 in 2000 to 113 in 2008 . Nearly $85 \%$ of crashes and deaths with public buses occurred within the city/ municipal roads and in 12 major geographical areas. Nearly $1 / 3$ of deaths occurred at the crash site, $22 \%$ during transportation and $44 \%$ in the hospital. Three of four deaths included road usears of $<35$ years and involved pedestrians $(28 \%)$, two wheeler riders $(40 \%)$ and bus occupants $(16.3 \%)$. Young drivers ( $<25$ years) were involved in more crashes with median age of fleets being 8.3 years. Several risk factors in vehicles, roads, environment and among road users were identified.

Public transport systems have a major responsibility and needs to have scientifically developed policies and programmes to ensure safety of citizens, both inside and outside vehicles. 